\title{
Communication of Tactile Experiences in Handcraft Decorations
}

\author{
Hee young $\mathrm{Kim}^{1} \& \mathrm{Ji}$ soo $\mathrm{Ha}^{1}$ \\ ${ }^{1}$ Seoul National University, Republic of Korea \\ Correspondence: Ji soo Ha, Seoul National University, Republic of Korea. E-mail: jisooha@snu.ac.kr \\ Hee young Kim, Seoul Nathional University, Republic of Koreal. E-mail: sindawn@snu.ac.kr \\ Received: July 19, 2016 \\ Accepted: July 28, 2016 \\ Online Published: August 31, 2016 \\ doi:10.5539/ach.v8n2p167 \\ URL: http://dx.doi.org/10.5539/ach.v8n2p167
}

\begin{abstract}
This article addresses the important role of tactile experiences in fashion design and consumption focusing on handcraft decorations through examining various experiences of consumers and designers in Korea. In-depth interviews are conducted based on the preliminary literature reviews and questionnaire survey and 20 general fashion consumers and 20 fashion designers participate in the interviews. Firstly, we check their recognitions about handcraft decorations on clothing, which are one of the most representative examples of handwork in fashion design. To find out what can be induced from tactile experiences of handcraft decorations, various pleasures with their handcraft decorated clothes are separately understood in two different situations of the process of making and touching. According to the designers' interview result, it is possible to form a sympathetic relationship between designers and materials as communicating each other through the tactile experience as using hands. In this procedure, creators come to be immersed more into the work and feel the pleasure of labour. In the consumers' cases, tactile observation as touching the handcraft decorations stimulus sensible pleasures exploring the materials and also makes them understand the creators' endeavour and time investment on the decorated clothes and feel empathy to them.
\end{abstract}

Keywords: fashion design, handcraft decoration, handwork, tactile sense, haptic

\section{Introduction}

Along with the extreme pursuit of efficiency in the fashion industry, handwork is often avoided in contemporary fashion design because it requires not only a high level of technical skills but also considerable time and effort. Handcraft decorations are easily underestimated as mere details seemed to be extraneous to the intrinsic form of clothes, composing only just some parts of it. However, it is still clear that delicately well-made handcraft decorations can increase the clothing's value, as making consumers recognize the designers' and manufacturers' endeavours from the product. Korean fashion market is rapidly changing and clothing is becoming depreciated consumed with an unpredictable trend style but they are also giving a value on the handcraft decorated clothes attaching a great meaning of elaborately produced creature on it.

This research identifies how both Korean designers and consumers recognize handcraft decorations of clothing which are one of the most representative examples of hand working creation in fashion, and analyses what they feel in the process of making and touching them with their own hands. Through investigating their actual experiences on the handcraft decorated clothing by in-depth interviews, it will be helpful not only to understand the implicit meanings of the fashion decorations especially emphasized with manual activities, but also to figure out which values can be derived from the active using of tactile sense at the process of creating and consuming fashion in Korea. Consequently, this study tries to point out the importance of our sensual experience and change the perspective on clothing from being concentrated on its commercial aspects to moving a focus on humans who create and consume it.

\section{Methodology}

This study includes both literature and empirical research. All of the participants for the empirical research were Korean women. The Korean industry is rapidly expanding and the fashion market is receiving great attention especially in connection with Korean entertainments (Park, 2015). Moreover, as Korean women generally show the high fashion involvement, it will be helpful to understand the contemporary Asian fashion market from the study of Korean fashion consumers. 
In order to organize in-depth interview questions and interviewees, a preliminary questionnaire was administered to 159 women whose ages were 20s to 50s range and who reside in Seoul. The questionnaire was comprised of topics including the definition, price, quality, and design characteristics of handcraft decorated clothing. Questions surrounding the respondents' consumption behaviours such as clothing purchases, wearing, and disposal were also included.

The in-depth interview questions were organized based on the results of the preliminary survey. To account for designers and consumers' different situations separately, the content and flow of the questions were planned differently and several additional questions were asked of the creators apart from the common questions with consumers. Interviews were conducted flexibly according to the flow of each conversation and roughly guided with semi-structured questions. It took about 40 90 minutes for each interview and all of them were recorded with participants' consents. Also, participants were asked to bring their clothes which they regarded as a handcraft decorated clothing to the interview and the clothes used in interviews were photographed as shown in this article.

In both cases, personal experiences with handcraft decorated clothes, especially related to tactile characteristics, were examined concretely and interviewees explained how these experiences affected the process of clothing purchase, wearing, and disposal. Additional questions for creators contained how they felt and what kind of the values could be generated from the process of design and produce of handcraft decorated clothing. Interviewees were segregated into two groups consisting of general consumers and fashion experts as the creators. All the participants of the in-depth interview were women between the age of 20 to 40 with undergraduates degrees or higher. There were total of 40 interviewees: 19 general consumers and 21 fashion experts including designers, manufacturers and postgraduate students. The interviews were conducted from May to June 2014.

\section{Recognition about Handeraft Decorations}

In the preliminary survey, respondents used specific words related to hand or manual activity to define handcraft decorations of clothing. 'Hand', 'handwork', and-'handmade' were the most frequently cited (54\%), and also 30\% of the participants noted a 'machine' as a concept contrasted to human handwork. This indicated that the production method based on human labour using their hands directly was the most strongly recognized in the handcraft decorations, implicating that it made consumers evaluate the clothes as higher values.

In the in-depth interviews, fashion experts showed a prominent tendency to mention handwork or manual labour producing to explain the concept of handcraft decoration of clothing. Many interviewees, using the words 'with every single stitch', emphasised elaborate and delicate handcraft decorations made by human hands.

'It is a work people do with their own hands, embroidered with every single stitch.'

$$
\text { Park, 36, postgraduate student }
$$

'Made directly by a person with every single stitch'

$$
\text { Lee, 32, postgraduate student }
$$

In addition, while using the words 'taste of hand touch' frequently, interviewees emphasized creative human hands as explaining the traces of handworks on the material. Such positive perspective on human labour contrasted with speed-oriented machinery production had an influence on increasing the value of handcraft decorated clothing.

'Things making me feel 'taste of hand touch' and see them for a long time.'

'I love such 'taste of hand touch'. Though it's worn out, still I wanna have it.'

Lee, 31, jewellery designer

Kim, 26, office worker

The time spent on intensive handwork was contrasted with mass production, thus this contributed to the rarity value. Some interviewees mentioned the artisan rarity of handcraft decorated clothes with handcraft decorations, thereby giving them a special value. Also, the handwork production method generates subtle differences in each product and such inevitable variances make people think the clothes as a unique creation made by humans rather than standardized mechanical production. Accordingly, the characteristics of handcraft decorations induced the consumers' careful observations and attention.

'It is made by an artisan with every single stitch. It is expensive because it has a rarity value' Jeong, 30, postgraduate student

'Every handwork decoration is different. It looks like the only one.'

Hwang, 27, postgraduate student

'My blouse looks like handcraft cause each cutting decoration looks different.'

Choi, 27, office worker 
In the preliminary survey, respondents mentioned the most beading $(85 \%)$ and embroidery (51\%) as the handcraft decorations technique (a duplicate item response). There may be various details decorating clothes by handcraft methods but it showed consumers had limited recognitions on the techniques to express handcraft decorations of clothing mainly as beading and embroidery. Besides, some in-depth interviewees connected some decorations to handcraft decorations if they showed irregular characteristics (Figure 1).
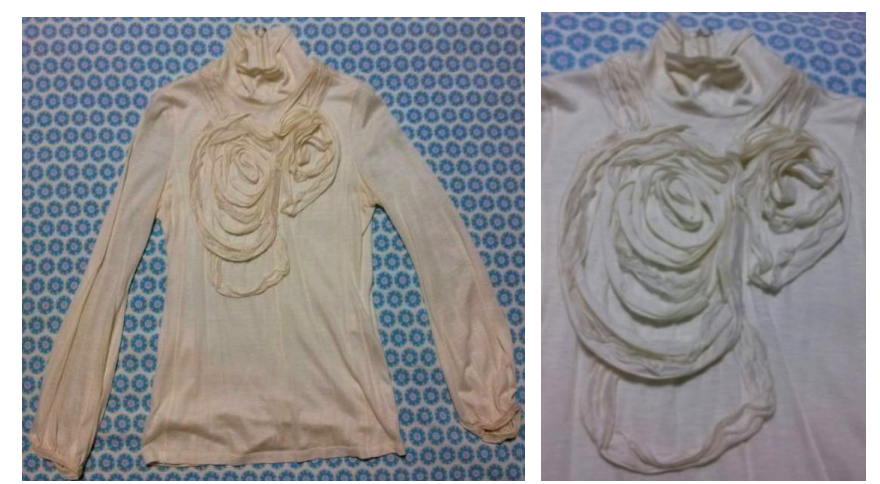

Figure 1. Irregularity charateristics in handcraft decorations of clothing

As for the specific image of handcraft decorated clothing design interviewees had, it was limited into feminine and fancy style and most of the clothes they actually brought were corresponded with this image (Figures 2, 3, 4). A great number of participants' clothes from the interview were high-priced and according to this, handcraft decorated clothing was perceived as an expensive luxury image considered with human labour cost invested for producing to the interviewees.

'Things made by hand, feminine clothes having beads or embroidery' (Figure 2)

Joo, 26, postgraduate student

'Handcraft decorated clothes looks very feminine. So, I feel like feminine and elegant whenever wearing them.' (Figure 4)

Kim, 38, musician

'Handcraft decorated clothes may be found mainly from designer's expensive brands'

Choi, 27, office worker
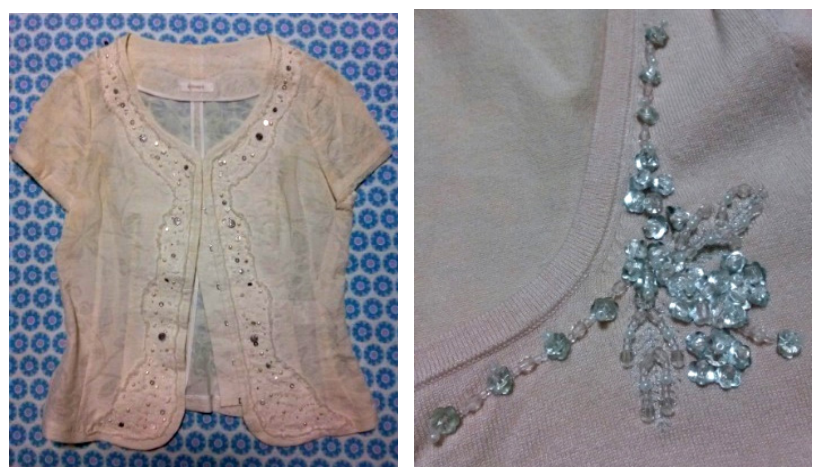

Figure 2,3. Beading handcraft decorations

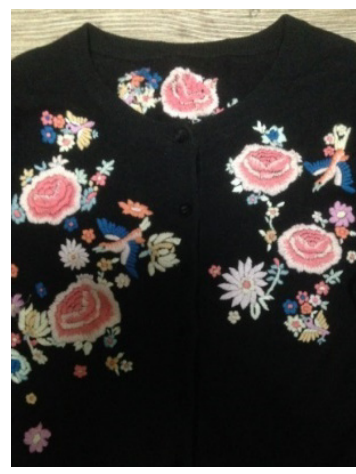

Figure 4. Embroidery handcraft decorations

Consequently, based on the recognition of interviewees, handwork production method was particularly highlighted in the handcraft decorations of clothing and they gave great values on the rarity derived from the 
characteristics of human handwork, which was contrasted with rapid machinery production. Besides, many of interview participants thought the handcraft decoration technique as beading and embroidery, and the general image of handcraft decorated clothes was feminine and fancy style, which also reminded high-priced luxury brands. This research pays attention to the meaning and value of handcraft decorations of clothing, focusing on their significant characteristics related with tactile sense. With two different dimensions of creators and consumers' situation, a pleasure of making by handwork and pleasure of touching by hands will be figured out concretely through in-depth interviews with them.

\section{Pleasures of Making by Handwork}

\subsection{Hands as a Physical Instrument}

The hand is the most useful instrument for human. Humans can survive by using their hands to utilize nature in harsh environments, turns ideas into realities, and to create civilization and culture through the hands. Instruments used in handwork function as an extension of the body and supplement the physical movement. However, instruments reflecting the physical movement of hands, arms and legs function differently based on the ability of a person who using them. With proficient handling skills, instruments become intertwined with hand movements and the instruments function as a part of the hands.

In creating craftworks based on handwork, both sophisticated technical knowledge of materials and a high degree of technical manual skills are needed (Risatti, 2007). The specific technical materials knowledge is factual information explained in text, and the manual skills for turning real material into form are acquired through innumerable practice repetitions that result in muscle memory. Sufficient technical knowledge of materials is fundamentally required for handcraft decorations. This knowledge can be easily acquired through indirect experiences found in books. However, it is difficult to develop a concrete design from materials without the practical hand skills necessary to delicately handle the material. In the technical expression of handwork, technical limitations that cannot be resolved by other instruments restrict the form. As such hand skills become embedded and engraved knowledge in our bodies, developed through the process of numerous experiences (Sennett, 2008) and considerable learning periods. Specialized handwork techniques make it possible to manage materials freely and generate a certain work rhythm once the technique is familiar. A body moves more rapidly in a rhythm and numerous variations can be generated while the individual is at ease with a work. The individual continues to discover new interests in the present work. There is an opportunity to pursue change and possibly create a completely different work rather than reproducing the same piece.

\subsection{Communication between Humans and Materials}

In handwork, humans are in close contact with materials, and exploration of materials creates novelties. As humans and materials become intimate, the human is influenced by the materials and a form is derived from its inherent potential. Feelings, emotions, and ideas involved in the creation are generated from the inner world of the worker; however, he or she can be significantly inspired by materials directly felt.

A plan which confines the completion decides the form's future (Bergson, 2009). However, a creative process with endless changes may have an unimaginable result. Design and materialization are performed simultaneously in the process of developing handcraft decorations and the use of complex senses results in repetitive corrections and changes. The hand gives momentary substance to intangible ideas and visible substance adjusts ideas again to complete the work. An initial design changes flexibly through the interaction of hands and eyes, and flexible completion creates more diverse results. As the work progresses and direction is acquired, the work itself becomes one's guide, thus continuously generating new possibilities.

In handcraft decorations, the worker uses integrated senses while directly identifying momentary changes and immediately transforming with his or her hand. The human affects the materials continually by projecting his self or herself onto the object, and the material change reacts upon the humans again so that the human and material interrelate as if they are speaking to each other. The fashion expert group interviewees who had experience in creating handcraft decorations frequently mentioned the repetitive corrections and changes that are characteristics of the handwork process. They were influenced by the continual subtle changes in the materials that created trivial differences and arrived at the completion based on such changes. Rather than following a monotonous path for a planned design, each part of the work could lead the entire work in a completely different direction through impromptu changes. 
'Changed a lot while working, wondering about whether to do this or that.'

Kwon, 38, knit designer

'There were many changes, seemed to be a little impromptu with the materials, rather than planned correctly.'

Hong, 28, fashion designer

'Instead of repeating the same things, I'll try to move in a new direction with it'

Kim, 31, postgraduate student

'I make it again and again if it is not pretty, till it comes to be pretty'

Hwang, 27, postgraduate student

Handwork is a continuous process of creating ideas rather than a simple repetition. The hands are creating a part of the present but the head plans the next step. Through the continual repetition of imagining and practicing with materials, every moment becomes a new process. The interviews indicated that workers who created handcraft decorations for clothes repeated changes to generate flexible results from the materials by constantly using their senses to understand the object tactilely by hands and to visualize the changes by eyes. This communication between human and materials enables us to generate a variety of possibilities that can originate from both of them.

\subsection{Pleasure of Labour}

Labour activities based on experienced handwork skills stimulate the workers. The body movement in which simple work for handcraft decorations repeated is not a labour to produce an immutable result. In an experimental process for which there was no fixed result, labour was similar to the experience of play as an immersion of voluntary activity, and thus accompanied tension and pleasure (Huizinga, 1964). If it results in the exploration of objects and satisfaction of self-expression, the work itself may be considered fun as in the essence of play. Extreme labour inevitably accompanies handcraft decorations, but it becomes play when one's ego is connected (Erikson, 1950) and work comes to be not a means to an end, but an aim to express one's self through materials.

'It is a continuous designing process, so there is no tedium... There is certain pleasure.'

Kim, 31, postgraduate student

'Tough and tired but interesting'

Kang, 31, postgraduate student

'Trying this or that with beads.... It makes me more motivated.'

Hong, 28, fashion designer

When a creator commits himself or herself to the material by focusing his or her entire body and mind on it, this intensive handwork greatly increases the result's value. Physical efforts represented by the creation produce a satisfaction with the work; this enhances the attachment relationship between creator and materials as well.

'Decided never to do it again, but it's rewarding once completed, so I make it again'

Hwang, 27, postgraduate student

'You tend to have attachment to handcrafts created by your own hands'

Nam, 31, fashion designer

'It is worth the challenging effort as you come to be more attachment'

Lee, 32, postgraduate student

Interest refers to a condition of self-engrossment in an object and discovering ones' self in some affair while becoming simultaneously lost in the effort (Dewey 1968:126). When asked for the reasons why they prefer handcraft decorations in fashion design, fashion experts said that they could express their thoughts with their hands and believed they were giving a life to a material by touching directly it. They could be absorbed into it, focusing their mind and entire body on the work. In a hard process of creating handcraft decorations, they have emotional empathy in the creations that reflect themselves. As more and more they immerse themselves in the work, strong emotional bond comes be formed between them, and creators feel an attachment with the creations. 
'Seems to be a work to which I give a breath'

Jeon, 26, knit designer

'It is a work that reflects myself and creates a new life.'

Kim, 31, postgraduate student

'If you make it by yourself with your hands, your mind will be absorbed in it.'

Hwang, 27, postgraduate student

'I feel much attachment while making it. Work hard with it, and have much attachment.'

Nam, 31, fashion designer

Therefore, handcraft decorations on clothes provide us with an opportunity to find pleasure in labour as we experience a material in which we can express our egos and feel a sense of accomplishment in the works. It originates from the characteristics of handwork, the work process for which varies based on the interaction between humans and materials through use of a physical instrument, which is their hands. Physical suffering and time investment in handcraft decorations also sets the high value for the clothes by creating an attachment to creators.

\section{Pleasure of Touching by Hands}

\subsection{Tactile Observation}

Tactile sense, one of senses which respond to external stimuli, is felt through stimulus or pressure that touches a sensory receptor on the skin with touching. Using the tactile sense to identify an object allows one to actively perceive an object by using every muscle of the hands, including fingers, in addition to simple skin touch. Touching makes an observer approach an object closely and experience it slowly in a static space in which the visible moment is suspended. Seeing creates distance and objectifies a matter, but the tactile sense removes this distance and allows mutual communication through direct understanding.

An interdependent relationship between tactile sense and visual sense has been found through a number of psychological experiments (Revesz, 1950; Katz, 1989; Klatzky, Lederman, \& Matula, 1991). The process of tactile sense involves exploring all parts of a matter slowly and collecting tiny details overlooked by the rapid visual sense. Seeing in the tactile sense is a close view that enables us to touch through the eyes (Deleuze, 2004) and leads an object into the centre of attention. However, relying on sight alone limits understanding to the superficial characteristics externally shown in the object. Visual information can be clearly identified by touching, and tactile information helps us to comprehend intrinsic characteristics of objects in a detailed manner. The relationship between the hand and the eye is infinitely richer, passing through dynamic tensions (Deleuze, 2004) and the tactile sense provides a high-dimensional experience through its interrelation with sight.

Tactile observation is derived from a desire to supplement visual information, but it is also driven by aesthetic pleasure. Aesthetic quality can be even affected by tactile information more than the visual input (Jansson-Boyd \& Marlow, 1997). The phenomenon of naturally raising our hands when we see the beautiful clothes occurs to maximize visual excitement and pleasure. Additional touching of what we see suggests an active observation approach to the object, which increases pure interest in the material aside from the consumption-oriented purpose. Handcraft decorations on clothes stimulate the tactile experience so that it induces us to adhere to the clothes and develop a keen interest in the item. This enables us to have various experiences with clothes, producing a diverse pleasure in them.

\subsection{Playfulness of Tactile Stimulus}

Handcraft decorations on clothes mostly provide, visual pleasure. The elaborate beauty of the decoration itself provides an observer with a visual playfulness, even when observed alone like artworks. These decorations attract the attention of passers-by, forcing them to a stop and approach the items closely. The following interviews suggested that clothes could provide pure pleasure derived from aesthetic appreciation, in addition to the pleasure of consumption or possession through wearing the item.

'There's pleasure in seeing but not wearing them'

Kim, 34, ballet dancer

'First, it attracts my eye. Pleasant to see it'

Kwon, 38, knit designer

'I always come closer and see them. Really enjoyable to even only see it'

Jeong, 30, undergraduate student 
Conspicuous attraction of handcraft decorations has a great effect on purchase of clothing. In general, clothing purchase is conducted through the complicated information processing, but it showed that purchase of handcraft decorated clothing tended to be on impulse buys. Accordingly, any risk about the size or wearability of the clothes was not the fatal obstacle on the purchase. The eye-catching attraction of handcraft decorations caused the purchase spontaneously even when it seemed certain that they could not wear the clothes. Without any purchase goals, consumers can enjoy touching products and also be engaged in compulsive buying (Holbrook and Hirschman 1982; Peck and Childers 2003a).

I buy such things while just wandering about. Buy it first, though it is not matching with me, though I regret later'

Jeong, 22, undergraduate student

'I didn't go for buying something but bought it without a second thought cause it caught my eyes'

Lee 32, postgraduate student

'I buy such clothes unconsciously. Without thinking whether I can wear it or not... sometimes I think I can not wear it. But I buy it cause I'd like to have it so much'

Kim, 34, fashion designer

'The size was big for me but I bought it just because of such handcraft decorations.'

Hwang, 27, postgraduate student

The pleasure of seeing with the eyes stimulates one's desire for touching with the hands. Tactile observation results from an urge not only to identify the actual visual images, but also to experience a three-dimensional figure or textural feeling. Handcraft decorations induce unconscious tactile appreciation arousing curiosity and pleasure; this differs from conscious observation used to acquire practical information. 'Touching', an activity in which one stretches his or her hand on purpose of aesthetically strong impressions or simple interest and curiosity, allows one to closely connect with an object and communicate with it through bodily experience. Hence, we can take more various interests in an object through the tactile exploration using our hands and have a different perspective on clothing not just as a consumption product but as an object for sensual aesthetic pleasure.

'I touch it naturally as if being attracted to something delicious'

Lee, 32, postgraduate student

'I've come to touch such clothes unconsciously because handcraft decorations have a unique, different feeling'

An, 28, postgraduate student

A preliminary questionnaire revealed that $91 \%$ percent of the respondents touched handcraft-decorated clothes when they saw them. This behaviour was not only for the practical purposes of obtaining information for purchase but also to satisfy simple aesthetical curiosity. In particular, handcraft decorations on clothes stimulated tactile experiences because of their solid shape textures and material objects can be perceived differently as having a relationship with human body. Perception based on speculated interest suggests awareness rather than simple physical perception (Bergson 2005: 28) and content and depth of awareness differ from personal interest and taste. In the observation of an interesting material object, perception through the tactile sense makes the observer's understanding much deeper than using only visual sense.

'It has a sense of volume, a characteristic you can feel only when you touch it'

Jeong, 30, postgraduate student

'It may appear as a flat image but it is a different tactile feeing when I touch it'

Lee, 31 , accessory designer

'When touching it, I felt as if I were seeing it more closely'

Seong, 30, office worker

Active touch can be regarded as 'tactile scanning', which is an exploratory rather than a merely receptive sense (Gibson, 1962). Handcraft decorations of clothing stimulate an observer to perform the information search process much actively, bring him or her to the object more closely with curiosity. The tactile approach on three-dimensional surface induces observer to spend much time for the slow exploration, so the object can have more meanings not just as the simple visual image. This active observation behaviour on handcraft decorations 
provides an opportunity for consumers to experience various pleasures with clothing. In addition, haptically oriented people who have a high "Need For Touch(NFT)" which means a preference to touch, are more likely to use tactile information for product evaluation (Peck and Childers 2003a; Peck and Childers 2003b). These haptically motivated consumers need to be provided enough tactile information to compensate their inability if they cannot experience a product directly through touch (Petty, Cacioppo, and Schumann 1983).

'I stop and see such decorations while walking along the street. Wondering how it was made'

$$
\text { Joo, 26, postgraduate student }
$$

'I see it back and forth. See it cause firstly, it's pretty and then see in detail, wondering the way how it was made...'

Kim, 26, office worker

'I touch it to know what was done with it. It attracts my attention'

Park, 35, teacher

'Feel great if I touch it. I see closely to know what they use to make it'

Choi, 27, office worker

Handcraft decorations can form the central meaning of the clothes though they are used for just some part of it (Figure 5). Decoration is generally supposed to be an additional element to decorate an object rather than playing an essential role, however handcraft decorations are giving the core meaning on the clothes in these interviewees' experiences. The decoration takes a central role in the design representing the entire clothes and acts the deciding factor to make consumers buy it as giving strong impression to them.

'I buy such clothes because the decorations are pretty. Without them, I will never buy the clothes.'

Park, 35, teacher

I bought the clothes because of it. I think handcraft decorations differentiate the clothes from others, giving the vitality'

Seong, 30, office worker

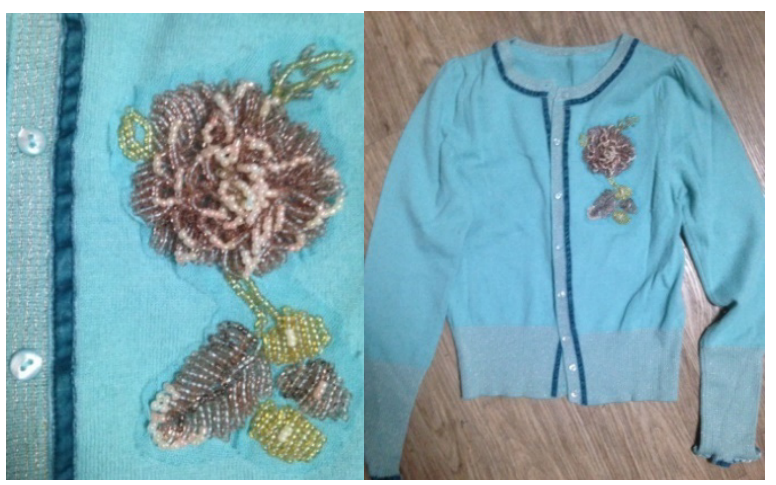

Figure 5. Handcraft decorations performing the key role of the clothing

\subsection{Empathy between Humans}

As it is related with humans, matter is interpreted to have special meaning it did not previously have and thus given special values. Handcraft decorations on clothes made by humans reflect time and effort. Intangible values are visualized into the matter and involved in a relationship with others through communication with tactile sense. Making an effort to appreciate handcraft decorations with using their hands can produces emotional empathy between the observer and the creator.

In the preliminary questionnaire, with regard to the recognition of handcraft decorations en of clothes, $92 \%$ of respondents replied, 'The creator's greater efforts must be considered'. In the same vein, in on the same question of the in-depth interview, interviewees indicated and highlighted the value of a creator's efforts frequently, explaining their recognition with the handcraft decorated clothes. 
'I begin to think about the creator. When touching, I think he or she must have toiled hard.'

Hwang, 31, office worker

'I think "How can a person do as this? She must have a pain in her shoulder'. ' (Figure 6)

Kim, 38, classic musician

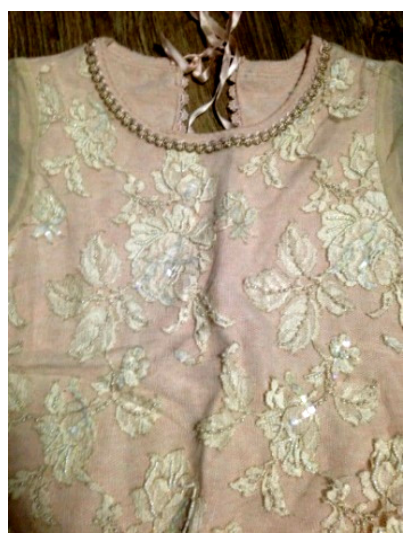

Figure 6. handcraft decorations (beading) evoking creator's efforts

Since human experiences and ideas are reflected in the work, the material can represent a human and convey them to others as a medium. Experience can be shared with others and make us understand the suffering process of creation even though we cannot see it directly. The efforts and toils the observer has perceived from the handcraft decorations triggered the emotion of empathy with the creator, and this attaches higher value to the material clothes again.

'It needs more devotion to create it. Therefore, it attracts people to buy it.'

Kim, 26, office worker

'It is an elaborate dress, so I think it has the value of "time".'

Lee, 31 , accessory designer

If we throw away a something, it means we do not have any value on it (Papanek 2000: 87). The reason why we avoid disposing and continually keeping clothes is that they have other valuable meanings even though we cannot wear it. These values make us feel as if we should not throw the clothes away carelessly because it reflects another person's time and effort used to make them. Accordingly, handcraft decorations of clothing have the positive effect on the disposal of clothing due to the significant value imposed by a relationship with others.

'A person made it over a long period of time, so it is too precious to throw away even if it gets worn out.'

Hwang, 27, postgraduate student

'I can't throw away such elaborate clothes even though they are unwearable.'

Kim, 34, fashion designer

In addition, handcraft decorated clothing is often perceived with artistic value similar to artworks. This leads them to be highly rarity, and easily differentiated from mass productive ready-made clothing. In the preliminary questionnaire, $72 \%$ of the respondents cited that handcraft decorated clothing seemed to be 'more artistic'. Likewise, interviewees demonstrated a tendency to give higher artistic values to handcraft decorations of clothing. These values also allowed them to remember the brand name of the clothes as if remembering an artist for his or her artwork.

'Handcraft decorations have artistic values rather than simple hand-made ones.'

Park, 35, teacher

'I think it's a method for sublimating general clothes to an artwork.'

Lee, 32, postgraduate student

'The brands with impressive handcraft decorations seem to be really valuable and artistic.'

Choi, 28, office worker 


\section{Conclusion}

Clothes we can touch with our hands, that surround our skin and move with us, have become estranged from our sensory pleasure. 'How does it look' has become more important with regard to clothing as a product, and it is converted into two-dimensional images to be consumed rapidly. Indirect experiences with product images on the internet degenerate our tactile exploration on the clothes, and decrease the opportunity to take the various pleasures derived from active and comprehensive sensual activities. However, many researches show that consumers prefer to select products when they are allowed to touch the product, especially in the case of product for which tactile information is important for evaluation such as clothing (McCabe \& Nowlis, 2003; Grohmann, Spangengerg, \& Sprott, 2007).

Handcraft decorations of clothing are made by creative handwork and stimulate hand observation by touching. They let us interact with materials and connect to others through tactile experiences. A creator communicates with materials by using his or her hands, the most useful human instrument. The result of the work is flexible as he or she repeats creating and transforming continuously, affected by the materials. The creation process characteristics of handcraft decorations promote sensory activities, which drives a creator to take pleasure in the work as he or she experiences self-oblivion while immersed in it. This eventually changes a physically intense labour into an enjoyable creative production which can be perceived as play, and forms an attachment relationship between the creator and the clothes, thus maximizing the achievements and satisfaction.

Furthermore, handcraft decorations of clothing stimulate the tactile senses, narrowing the distance from a material object and increasing interest in it. Consumers' playful tactile observations by 'touching', provide deep and rich understandings of clothing to discover various values as it becomes integrated with the observer's internal imaginations and feelings. Traces of delicate handwork allow us to estimate others' time spent in the endeavour, and the clothing comes to be considered a rare creation made by human hands, not a simple product. In this way, handcraft decorated clothing functions as a medium between humans that could possibly generate emotional empathy and influence changes in consumption behaviours, including the disposal of clothes.

Focusing on the handcraft decorations of clothing that tactile sense is particularly emphasized, this study examined their meaning inherent in the recognition of both creators and consumers based on their experiences and can help us understand various aspects of Korean fashion market. We identified diverse pleasures and values from their making and touching process with tactile activities, and found out that these tactile experiences could make it possible to communicate between human and materials and also human and human.

\section{References}

Bergson, H. (1991). Matter and Memory. In N. M. Paul, \& W. S. Palmer (Trans.). New York: Zone books.

Bergson, H. (2009). Creative Evolution. In A. Mitchell (Trans.). Whitefish, MT: Kessinger Publishing.

Deleuze, G. (2004). Francis Bacon: The Logic of Sensation. In D. W. Smith (Trans.). Minneapolis: University of Minnesota Press.

Dewey, J. (1968). Democracy and Education: An Introduction to the Philosophy of Education. New York: The Free Press; London: Collier-Macmillan.

Erikson, E. H. (1950). Childhood and Society. New York: W.W. Norton \& Co.

Gibson, J. J. (1962). Observations on active touch. Psychological Review, 69(6), 477-491.

Grohmann, B., Spangengerg, E. R., \& Sprott, D. E. (2007). The Influence of Tactile Input on the Evaluation or Retail Product Offerings. Journal of Retailing, 83(2), 237-245.

Holbrook, M. B., \& Hirschman, E. C. (1982). The Experimental Aspects of Consumption: Consumer Fantasies, Feelings, and Fun. Journal of Consumer Research, 9(2), 132-140.

Huizinga, J. (1964). Homo Ludens: A Study of the Play-element in Culture. Boston: Beacon.

Jansson-Boyd, C., \& Marlow, N. (2007). Not only in the eye of the beholder: Tactile information can affect aesthetic evaluation. Psychology of Aesthetics, Creativity, and the Arts, 1(3), 170-173.

Kaz, D. (1989). The World of Touch. In L. E. Kruegeer (Ed.). NJ: Erlbaum.

Klatzky, R. L., Ledermna, S. J., \& Matula, D. E. (1991). Imagined Haptic Exploration in Judgements of Object Properties. Journal of Experimental Psychology: Learning, Memory, and Cognition, 17(2), 314-322.

McCabe, D. B., \& Nowlis, S. M. (2003). The Effect of Examining Actual Products or Product Descriptions on Consumer Preference. Journal of Consumer Psychology, 13(4), 431-439. 
Papanek, V. J. (2000). Design for the Real World: Human Ecology and Social Change. Chicago, III: Academy Chicago.

Park, J. (2015). Star Power in Korean Fashion: The Win-Win relationship between Korean Celebrities and Designers. Fashion Practice, 7(1), 125-134.

Peck, J., \& Childers, T. L. (2003a). Individual Differences in Haptic Information Processing: The "Need For Touch" Scale. Journal of Consumer Research, 30(3), 430-442.

Peck, J., \& Childers, T. L. (2003b). To Have and To Hold: The Influence of Haptic Information on Product Judgments. Journal of Marketing, 67(2), 35-48.

Petty, R. E., Cacioppo, J. T., \& Schumann, D. (1983). Central and Peripheral Routes to Advertising Effectiveness: The Moderating Role of Involvement. Journal of Consumer Research, 10(2), 135-146.

Revesz, G. (1950). Psychology and Art of the Blind. In H. Wolff (Trans). London: Longmans, Green, \& Co.

Risatti, H. (2007). A Theory of Craft: Function and Aesthetic Expression. Chapel Hill: University of North Carolina Press.

Sennett, R. (2008). The Craftsman. New Haven; London: Yale University Press.

\section{Copyrights}

Copyright for this article is retained by the author(s), with first publication rights granted to the journal.

This is an open-access article distributed under the terms and conditions of the Creative Commons Attribution license (http://creativecommons.org/licenses/by/4.0/). 